\title{
ACCELERATING CONSTRUCTION OF ROADWAY BRIDGES USING ALTERNATIVE TECHNIQUES AND PROCUREMENT METHODS
}

\author{
Ossama Salem, Baris Salman, Sudipta Ghorai \\ Dept of Civil and Environmental Engineering, Syracuse University, Syracuse, United States \\ Submitted 23 July 2015; resubmitted 20 April 2016; accepted 05 June 2016; \\ published online 02 May 2017
}

\begin{abstract}
Approximately a quarter of the bridges in the United States are classified as either functionally obsolete or structurally deficient by the United States Department of Transportation (USDOT). As such, transportation agencies are challenged to handle the increasing need of upgrades with limited resources. Accelerated Bridge Construction $(\mathrm{ABC})$ can reduce the construction duration and can decrease the environmental and socio-economic impacts of repair and upgrade activities by minimizing traffic disruptions. As several states are using accelerated construction techniques, a standard guideline would be highly beneficial for these agencies in developing or improving the $\mathrm{ABC}$ decision-making process. As problems are often project specific, a decision tool can assist in determining the viability of $\mathrm{ABC}$ over traditional construction methods and in selecting appropriate construction and contracting strategies on a case-by-case basis. This paper presents findings of a recent survey with regards to utilization of ABC strategies by state Departments of Transportation (DOTs), and a decision support framework which consists of three models: (1) Analytical Hierarchy Process (AHP) based ABC vs. traditional construction decision-making model; (2) ABC alternatives selection model; and (3) procurement method and contract selection model. The paper also discusses the use of ABC in New York State and describes a New York State bridge project to validate the AHP model.
\end{abstract}

Keywords: accelerated bridge construction; analytical hierarchy process; procurement methods; contracting requirements; decision-making models.

\section{Introduction}

According to the data provided by the American Society of Civil Engineers (ASCE), the average age of the 607380 bridges in the United States is 42 , and $11 \%$ of these bridges are categorized as structurally deficient and $13.9 \%$ are categorized as functionally obsolete (ASCE 2013). When the nation's bridges were evaluated in terms of factors such as capacity, condition, resilience, and future needs, an overall grade of $C+$ was assigned. Failure to address needs associated with structural deficiencies may result in bridge closures or traffic restrictions, which may result in severe socio-economic impacts (Reichman 1976). On the other hand, economic limitations and other competing needs are forcing federal agencies to limit the funding available to state Departments of Transportation (DOTs) to address those needs associated with highway bridges (AASHTO 2007). More specifically, according to ASCE, it would take the United States Department of Transportation (USDOT) around $\$ 20.5$ billion annually to improve the current situation of the bridges; whereas, USDOT has an annual budget of only $\$ 12.8$ billion for bridges (ASCE 2013).

As the needs associated with upgrades and repairs exceed available funds, decision makers are urged to determine the best use of limited resources. In a mature infrastructure system, upgrade or repair activities require either restriction or closure of parts of the system. Employing traditional construction methods during these activities cause traffic disruption, which frequently result in high user costs and raise issues of safety and congestion. A systems approach to accelerate infrastructure construction is required to mitigate the impacts of extensive upgrade and repair activities that are likely to take place in the near future (Blanchard et al. 2009). As several states are using accelerated construction techniques, a standard guideline would be highly beneficial for these agencies in developing or improving their Accelerated Bridge Construction (ABC) decisionmaking processes. Most often, the problems faced are project specific, which makes it challenging to choose

Corresponding author: Baris Salman

E-mail: bsalman@syr.edu 
among various rehabilitation methods. While $\mathrm{ABC}$ offers various advantages, in certain cases disadvantages such as higher initial cost, durability issues, design complexity, higher risk, and higher worker fatigue may jeopardize the viability of $\mathrm{ABC}$. Therefore, there is an urgent need for a planning tool that can identify the potential problems and provide the most feasible solution (Lee, Thomas 2007). This paper intends to address this need by presenting the results of a research study that focused on factors that affect the selection process of $\mathrm{ABC}$ Techniques (ABCT) and contracting methods and by providing a decision support platform that will assist in determining suitable acceleration strategies for a given bridge project.

\section{Background}

\subsection{ABC Alternatives}

$A B C$ alternatives can be widely categorized into $A B C$ Components (ABCC) and $A B C$ Techniques (ABCT). Currently, several $\mathrm{ABCC}$ are being used for faster project delivery and for minimizing interruptions to traffic flows. ABCC can further be divided into (1) Prefabricated Bridge Elements (PBE) and (2) Prefabricated Bridge Systems (PBS). A PBE refers to a single structural component of the bridge (Culmo 2011) and may include bridge decks, beams (Culmo 2009), pier caps (Ralls et al. 2005), columns, footings, retaining walls, abutments, or wing walls. These elements are fabricated off-site in a regulated environment and are then brought to the site for installation. PBS can be superstructures, substructures and/or complete bridge modules. Superstructure systems consist of modules of both deck and primary supporting members and can be placed on existing or new substructures with minimal disruption of mobility. Substructure systems, mostly abutments and piers, can also be included in the module (FHWA 2012). ABCT includes processes such as rapid embankment construction and foundation techniques. It also stipulates the transportation (FHWA 2007), lifting, and placement techniques (Culmo 2011) of the PBEs and PBSs. Several ABC alternatives that are currently used are summarized in Fig. 1.

\subsection{Procurement Methods and Contracting Requirements}

Procurement methods and contracting requirements play a vital role in accelerating construction projects. Design-Bid-Build (DBB) is the method traditionally used for delivering bridge projects (Hancher 1999). Despite of the familiarity of the parties with DBB and the lower amount of risk placed on the contractors, this particular project delivery system may present certain drawbacks: (1) the construction process cannot start before the completion of the design, which results in longer project durations; thus makes DBB not suitable for the expedited delivery of projects, (2) the owner stipulates the specifications prior to the construction phase, which leaves little room for innovation, as the contractor does not have any risks related to quality, performance or maintenance (Hancher 1999). Consequently, several innovative contracting or Alternative Project Delivery (APD) approaches have been developed throughout the United States, and it was found that these approaches may have the potential to result in faster completion of projects, especially at locations that face heavy traffic congestion.

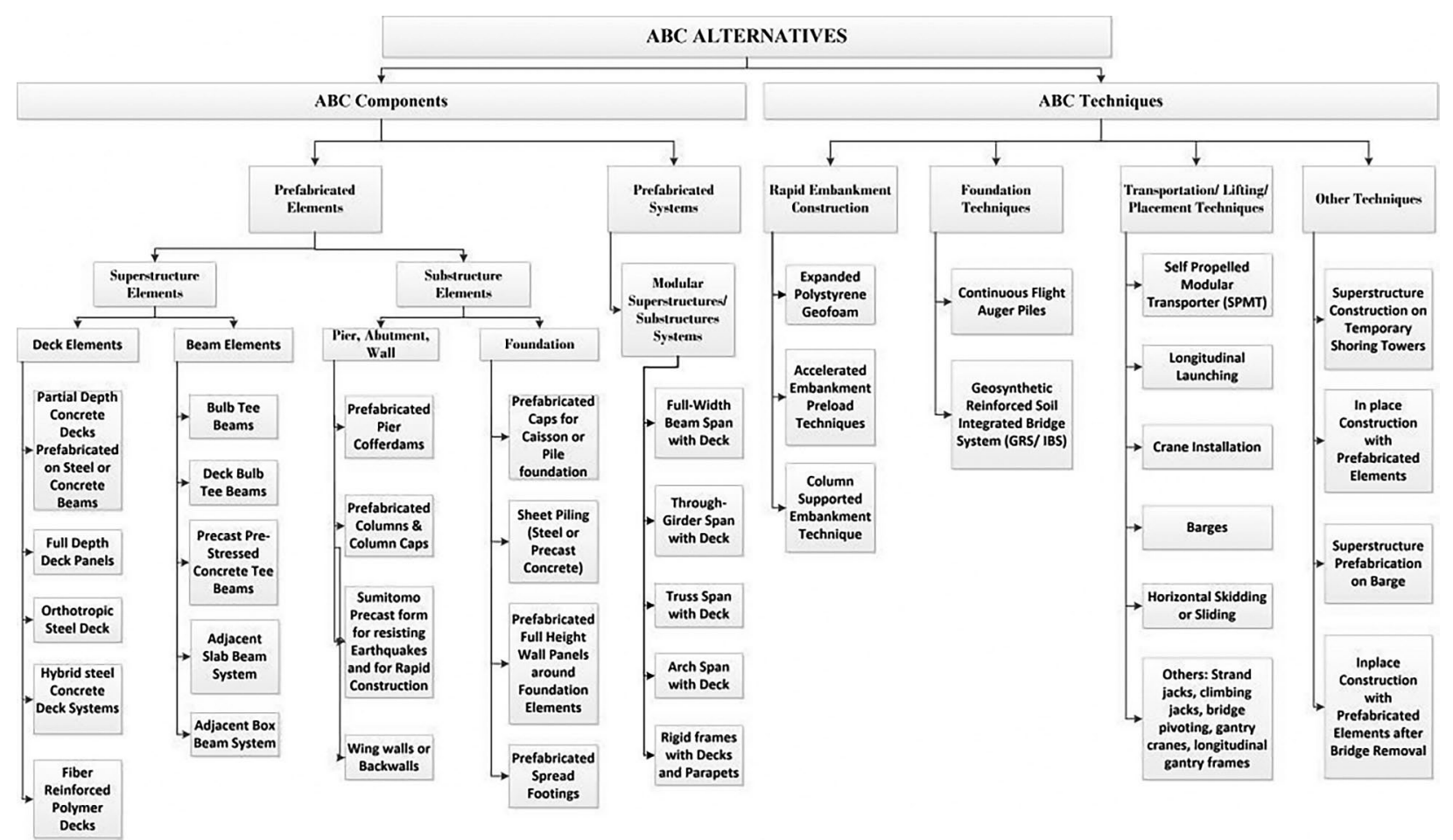

Fig. 1. ABC alternatives 
Alternative procurement methods encourage contractors to employ construction techniques and modern technology that improve the quality of the project, and/ or reduce the project duration. Accelerated construction requires effective communication between design and construction teams; as most often these phases are overlapped to complete the project in a fast track. Employing alternative procurement methods can result in lower cost-overruns that may otherwise occur due to schedule delays and/or change orders (Carpenter et al. 2003). Some of the innovative procurement methods used successfully in bridge construction projects are as follows:

- Design Build (DB): the public agency has a single contract with the company that is in charge of both design and construction (Fishman et al. 2009);

- Construction Management at Risk (CMR): the owner hires a Construction Manager (CM), who assumes the role of the general contractor, accepts the risk, and guarantees the price of construction (Mahdi, Alreshaid 2005); this procurement method is also referred to as Construction Manager/General Contractor (CMGC);

- Construction Management Agency (CMA): this procurement method is highly similar to the traditional procurement method, except that the owner hires a CM to control the project mostly during the design phase; in CMA, the CM's role is fully advisory (Mahdi, Alreshaid 2005).

Some of the contracting requirements that can be used with the above mentioned procurement methods are as follows:

- Lane Rental: The contractor is charged according to the time spent for construction activities occupying the traffic lanes (Carpenter et al. 2003). This is mainly intended to accelerate the construction process at locations where traffic volume is high;

- $A+B$ Bidding (also known as Cost-Plus-Time): Both initial construction cost and project completion time are used as decision-making criteria for contractor selection. The duration is converted into its corresponding dollar values by calculating the user cost, which is obtained by multiplying the user cost rate per day with the number of days of construction (Fishman et al. 2009). A+B can either be used alone or with other contracting requirements;

- Incentive/Disincentive (I/D): Inclusion of I/D clauses is one of the most commonly used options by the agencies to accelerate bridge construction. This clause can be included in any kind of procurement method. As the amount of incentive often depends on the time saved, and that of disincentive on the amount of overtime, it encourages contractors to shorten the construction schedule (Blanchard et al. 2009);

- Phased Construction/Multiple Contracts: These contracts can be used to reduce the construction time when the project scope is excessively large. In such a case, the project is divided into distinct contracts, which can be carried out separately at the same time. The contracts may be let to different contractors and can be carried out using different procurement methods (Hall et al. 2010);

- Advance Purchasing: Components having high lead-time can be purchased beforehand in order to prevent any delays due to material procurement procedures. Advance Purchasing can be employed in any procurement method (Salem et al. 2013).

\subsection{Existing Decision-Making Models}

The $\mathrm{ABC}$ decision-making process developed by the Federal Highway Administration (FHWA) provides a flowchart framework to select an appropriate construction technique under various scenarios (Culmo 2011). The factors considered for this model are site constraints, traffic management, right of way, existing utilities, and government regulations. The model consists of four different flowcharts: The first three are developed for the bridge superstructures over roadways or land, railroads or transit, and water or wetland, respectively and the fourth is developed for the substructure construction (Culmo 2011). In the ABC model developed by Utah DOT, specific weights were assigned to the factors considered in the decision-making process such that the weights were in accord with the department's objectives of decreasing user costs caused by delays, promoting innovation in the project delivery process, and maintaining the economic feasibility of the project. The rating score was calculated as the ratio of the weighted score to the maximum score possible and was expressed as a percentage. The $\mathrm{ABC}$ rating scores ranged from 20 to 50 and had three categories. Different categories had different entry points in the $\mathrm{ABC}$ decision-making flowchart, which were then used to draw a conclusion (UDOT 2010). Tang (2006) developed a PBE and PBS framework with an objective of determining the suitability of prefabrication for a given project. The framework consisted of a flowchart for high-level decision-making and a matrix of 22 questions for detailed analysis of various factors (Tang 2006). Oregon DOT prepared an ABC tool based on Analytical Hierarchy Process (AHP) to evaluate the feasibility of $\mathrm{ABC}$ over traditional bridge construction (Doolen et al. 2011). The framework features an economic modeling tool, as such it may be deemed as more suitable for detailed planning rather than high-level decision-making. The amount of information needed to use this model may not be available during the preliminary design.

In light of these studies, it can be concluded that there is still room for improvement in terms of the development of high-level decision support tools along with models that can be used to determine appropriate construction techniques and contracting alternatives on a case-by-case basis. The $\mathrm{ABC}$ decision-making framework proposed in this paper intends to address this gap. 


\section{Survey of State DOTs}

In order to gain a deeper understanding with regards to the current state of practice in utilization of ABCT and innovative procurement methods and contracting requirements, a questionnaire survey was generated and sent to a pool of officials from State DOTs electronically. In order to maximize the number of responses, the survey was limited to 10 questions. Responses were obtained from the following 21 state DOTs: California, Colorado, Connecticut, Delaware, Hawaii, Illinois, Iowa, Missouri, Nebraska, Nevada, New Jersey, New York, North Carolina, South Dakota, Texas, Tennessee, Pennsylvania, Utah, Washington, Wisconsin, and Wyoming. Details of the survey and responses can be found in the final report of the study (Salem 2013). Due to space limitations, only the highlights of responses to each question are provided in this paper:

- 18 out of 21 respondents indicated that their agencies have used accelerated construction strategies to reduce construction project delivery times in the last five years;

- based on 16 responses received, a large majority of the $\mathrm{ABC}$ projects (88\%) are planned bridge projects rather than emergency repair or reconstruction projects;

- based on the average values of 11 responses, $90 \%$ of the $\mathrm{ABC}$ projects were completed on or ahead of the schedule; $85 \%$ of the $\mathrm{ABC}$ projects were completed within or below budget; $93 \%$ of the $\mathrm{ABC}$ projects were completed with acceptable quality and workmanship, and almost all projects (99.4\%) were completed without any accidents;

- out of 18 respondents, 17 indicated that their agency utilized prefabricated components and 9 indicated that their agency utilized precast substructure components. Other commonly utilized techniques included stay in place steel forms (11 respondents), deckless bridges (adjacent box or bulb t-beam structures, 9 respondents), and use of heavy cranes/transporters (7 respondents);

- the most commonly used procurement methods among states that responded were DBB with incentives/disincentives (8 respondents), DBB (6 respondents), DB with incentives/disincentives (5 respondents), and DB (4 respondents). None of the respondents indicated utilizing lane rental or CMR in $\mathrm{ABC}$ projects;

- the following factors received the highest average rating values in terms of their impacts on the decision-making procedure with regards to whether ABCT should be used or not (Numbers in parenthesis indicate the average rating out of 10): Whether the bridge is a critical infrastructure element (bridge constitutes the only path to access an area, 8.9), impact on the traffic flow (8.2), safety (7.9), impact on community (e.g. reduced access, detours, emergency services, 7.9) impact on local businesses and large employers (e.g. airports, postal, package courier service, 7.5) and local events (beginning of school year, festivals, sports events, 7.4);

- the following factors received the highest average rating values in terms of their hindering effects on accelerating bridge construction projects (numbers in parenthesis indicate the average rating out of 10): necessity of coordination with railroad facilities (7.8), site conditions (7.2), non-availability of alternate routes for detours (7.2), and accommodation or relocation of existing utilities (6.7);

- for both emergency and planned bridge construction projects, initial cost was considered highly important. In emergency bridge construction projects, user cost had the same importance level as the initial cost. In planned bridge construction projects, user cost and life cycle costs had approximately equal importance values, which were slightly lower than the initial cost;

- in calculation of user costs, increases in travel times due to detours, and delays had higher priorities in comparison to safety, and disruptions to local businesses.

\section{State of Practice in New York State (Salem et al. 2013)}

\subsection{General Practice}

The authors met with the New York State Department of Transportation (NYSDOT) officials to understand the state of practice with regards to utilization of $\mathrm{ABCT}$ in New York State. NYSDOT uses ABC in cases of emergency construction, for repairs and replacements at locations experiencing heavy traffic, in case of a need for a compressed schedule (e.g. prior to local events) and for constructing in adverse weather conditions (winter construction). To reduce impacts on the existing traffic, NYSDOT opts for nightly closures or weekend closures.

Some of the contracting methods or techniques implemented by the agency are mandated shorter construction time, $\mathrm{I} / \mathrm{D}$, value engineering, best value, $\mathrm{DB}$, and advance purchasing. Value engineering encourages contractors to propose innovative construction methods that are outside the original design and may help in improving the quality of the finished product and/or reducing construction time. The best value method is often used to optimize the trade-off between price and performance.

In November 2011, NYSDOT was granted permission to use DB delivery for the next three years. DB is not permitted in many state DOTs due to several reasons:

- DB does not always provide the least-cost delivery;

- DB presents difficulties for local and small contractors to compete. DB requires contractors to perform a large amount of engineering design work prior to bid submission; if the contractor is not awarded with the contract, all these efforts are wasted; 
- the owner has less control over Quality Assurance and Quality Control (QA/QC); QA/QC aspects represent some of the most challenging duties for the agency in this type of contractual arrangement;

- the finished product may not have the desired quality;

- DB projects initially had a tarnished history.

Advance purchasing is another strategy followed by NYSDOT to acquire construction materials (such as steel bearings) ahead of time so as to prevent further delays due to time-consuming purchasing processes. For any kind of delivery, it is important to incorporate the material purchase and delivery time into the schedule. In advance purchasing, the burden is on the fabricator. Strong coordination between design, fabrication, and construction is required. Accurate planning and scheduling is highly important.

For emergency ABC, NYSDOT has a predetermined list of contractors for immediate action. These projects are executed based on a force account. They can be considered as DB type projects that are run by the agency. The contractor with the lowest bid undertakes the construction work provided that the contractor agrees to finish the project on a certain day. The agency has also directed emergency projects by accelerating the DBB process with expedited design, bidding and best value contractor selection components.

NYSDOT engages a case-by-case decision process for selecting $\mathrm{ABC}$ over traditional methods. Some of the factors considered by the agency are appropriateness of $\mathrm{ABC}$ for the project, whether $\mathrm{ABC}$ adds any value to the project, experimentation purposes, and dealing with emergency situations. Disadvantages associated with $\mathrm{ABC}$ are listed as higher cost, durability issues, design complexities, construction complexities, and challenges faced in dealing with uncertainties (for example, presence of more severe damages than anticipated).

\subsection{NYSDOT ABC Projects}

In this section, some of the $\mathrm{ABC}$ projects undertaken by the agency are briefly described. General characteristics of the projects, $\mathrm{ABC}$ technologies used, and some of the challenges faced are provided.

Cross Bay over North Channel 87 Viaduct. The bridge is 2842 feet long. It consists of 34 spans and has 3 lanes. Some of the elements used for the project were cylinder piles, precast pier caps forms, pre-stressed I beams, diaphragm forms and partial depth precast deck panels. One of the issues faced was the tendency of deck joints to crack.

I-287 Cross Westchester Expressway Viaduct. Use of $\mathrm{ABC}$ allowed the agency to save one year, and thus achieve a $50 \%$ reduction in the project duration. The elements used for the project were precast piers, precast decks (full width), post tension decks, 2 inch concrete overlays and open transverse joints. It is reported that some issues arose while grouting the connections as the post-tensioning ducts were getting clogged.
Route 31 over Canandaigua Outlet. The key elements used in the project were deck bulb tee with Ultra High Performance Concrete (UHPC). This project was one of the first applications of UHPC joints in the area. Some of the properties of UHPC are extraordinary bond strength, superior durability, high compressive and tensile strength, low drying shrinkage, fast strength gain, and the capability to develop a full rebar within a 6 inch wide joint. It was also indicated that the UHPC joints provide a moment connection, whereas regular grout provides only shear connections. Some of the challenges associated with this project were reported as camber issues and overlay issues due to difference in levels.

Route 23 Over Otego Creek. Some of the elements used were precast with UHPC joints, which eliminated the need of any post tensioning and helping to reduce the thickness of the decks. This project was undertaken on an experimental basis. Integral abutments were also used.

Route 9 W over Cedar Pond Brook. Advance purchasing was used in this project, which saved $50 \%$ of the construction time. Materials were purchased beforehand and stored in the agency warehouse. In cases where the space available was not sufficient, residential areas were temporarily rented for storage. Arrangements were made with the vendors to ensure delivery of the materials to the site on specified dates and time. For this project a certain date of completion was determined and a liquidated damage clause was included in the contract.

Route 32 over Kaaterskill Creek. The bridge was originally built in 1941 . The state decided to rebuild the structure. Integral abutments were used in the new design. An existing span, which was salvaged from another bridge (9P over I87 - Exit 14 of Northway), was installed on site. The elements used were adjacent box beams. Steel used in this project was procured in advance.

Seven Lake Dr/Ramapo River. This project involved construction of several temporary bridges in order to provide access to the villages in the area. Failures in spread footing caused formation of cracks in the superstructures. Foundations were undermined. Some of the bridges included utility lines. It is indicated that coordination with utility companies proved to be one of the most challenging tasks in this project. Public involvement was another important factor in accelerating the construction. The agency officials reported that the agency sometimes avoids $A B C$ if the bridge is located over utilities or railroads due to difficulties faced in coordination.

\section{ABC Decision-Making Framework}

The $\mathrm{ABC}$ decision-making model presented in this paper consists of two sequential phases. The first phase assists in high-level decision-making where the stakeholders can evaluate the suitability of $\mathrm{ABC}$ over traditional construction using an AHP Model. Variants of AHP have been applied to various decision-making problems in construction and bridge management (Pan 2008; Mahdi, Alreshaid 2005; Youssef et al. 2005). If ABC is found 
to be favorable for a given project, then the decisionmaking process continues with Phase 2; otherwise traditional construction methods should be selected. Phase 2 features decision-making flowcharts and provides guidance on selection of appropriate ABCC or ABCT, and procurement methods or contracting requirements.

\subsection{Phase 1: ABC vs. Traditional Construction Decision-Making Using AHP}

AHP is a flexible pairwise comparison model, which can be customized according to the decision maker's needs depending on the nature of the problem (Saaty 1980). Some of the reasons for selecting AHP as a tool to develop the decision-making platform in Phase 1 include the following (Saaty 1980):

- AHP helps in understanding the problem in a more systemic way through repetition so as to have a clear definition of the problem to facilitate proper judgment and logical decision-making;

- it allows users to consider the relative priorities of attributes in a system to select the best alternative among the potential candidates for a given goal;

- it provides the user with a scale to measure intangible factors and also helps in placing priorities to factors;

- it allows interdependence of elements in a system without insisting on linear thinking.

Steps followed in developing the decision-making model in Phase 1 are as follows:

Step 1: Defining the Problem and the Desired Goal. The objective of Phase 1 is to evaluate the viability of ABC against traditional construction methods. The goal of a typical bridge construction project is to complete the project in the least amount of time in an economical manner with minimum effects on the existing traffic, nearby community, businesses, and surrounding environment, and without compromising safety and longterm performance.

Step 2: Structuring of Hierarchy from an Overall Managerial Point of View. In this step, the important fac- tors that affect the decision-making process with regards to suitability of $\mathrm{ABC}$ for a bridge construction project are determined. First, decision makers may identify higher-level factors and then divide these higher-level factors into sub-factors. Thus, a hierarchy of important factors that affect the decision-making process is generated.

Step 3: Forming the Pairwise Comparison Matrices. The factors at the lowest level of the hierarchy are compared against each other in a pairwise format to determine their relative importance with regards to the parent factor. While comparing two elements, it is often preferred to express dominance as a whole number. In the comparison matrix, each element on the first column of each row is compared to other elements placed at the column heads regarding their dominance. Thus, the matrix is designed so as to have reciprocal values in diagonally opposite cells.

The scale used in pairwise comparisons is presented in Table 1 . The scale contains all the integers from 1 to 9 , each number denoting a certain level of importance between elements or properties. The ideal way to use this scale is to decide on the verbal interpretation of the points and then to assign the corresponding value to a comparison, while considering social, or political problems.

Step 4: Calculating Eigenvalues and Eigenvectors to Find Relative Weights. The eigenvectors of the factors are calculated to determine the relative weights of the criteria. The formula for calculating eigenvector with the principal eigenvalue of a matrix $A$ is as follows:

$$
\lim _{k \rightarrow \infty}\left(\frac{A^{k} \cdot e}{e^{T} \cdot A^{k} \cdot e}\right)=C \cdot w,
$$

where: $e$-column vector; $e^{T}-$ transpose of column vector $e ; C$ - constant; $w$ - eigenvector.

Several approximate methods have been developed to calculate the eigenvectors. Among these, Saaty (1989, 2012) recommended the Average of Normalized Column technique as it gives the most accurate approxi-

Table 1. Ratio scale for AHP pairwise comparison (Doolen et al. 2011; Saaty 2012)

\begin{tabular}{|c|l|l|}
\hline $\begin{array}{c}\text { Intensity of } \\
\text { importance }\end{array}$ & \multicolumn{1}{|c|}{ Definition } & \multicolumn{1}{|c|}{ Explanation } \\
\hline 1 & Equal importance of both elements & Two elements contribute equally to the property \\
\hline 3 & Weak importance of one element over another & $\begin{array}{l}\text { Experience and judgment slightly favor one element } \\
\text { over another }\end{array}$ \\
\hline 5 & $\begin{array}{l}\text { Essential or strong importance of one element over } \\
\text { another }\end{array}$ & $\begin{array}{l}\text { Experience and judgment strongly favor one element } \\
\text { over another }\end{array}$ \\
\hline 7 & Demonstrated importance of one element over another & $\begin{array}{l}\text { An element is strongly favored and its dominance } \\
\text { is demonstrated in practice }\end{array}$ \\
\hline 9 & Absolute importance of one element over another & $\begin{array}{l}\text { The evidence favoring one element over another } \\
\text { is of the highest possible order of affirmation }\end{array}$ \\
\hline $2,4,6,8$ & $\begin{array}{l}\text { Intermediate values between two adjacent judgments. } \\
\text { Intensities } 1.1,1.2,1.3 \text { etc. can be used for elements that } \\
\text { are very close in importance }\end{array}$ & Compromise is needed between two judgments \\
\hline Reciprocals & $\begin{array}{l}\text { If activity } i \text { has one of the preceding numbers assigned to it when compared with activity } j \text {, then } j \text { has the } \\
\text { reciprocal value when compared with } i\end{array}$ \\
\hline
\end{tabular}


mation of the eigenvectors (Saaty 1982). Details of this procedure can be found in Salem et al. (2014).

Step 5: Checking the Consistency of the Matrices. The consistency of a comparison matrix measures the reliability of a decision maker's judgment. Consistency should be checked at various stages to ensure comparisons and resultant conclusions are reliable. For a positive reciprocal matrix to be consistent, the largest eigenvalue should be equal to the order $n$ of the matrix. The positive reciprocal matrix is said to be inconsistent if the eigenvalue is greater than the order of the matrix. Consistency of the matrix can be measured by the Consistency Index (CI), which can be calculated using Eq. (2) (Saaty 1980):

$$
C I=\frac{\lambda_{\max }-n}{n-1},
$$

where: $\lambda_{\max }$ - maximum eigenvalue; $n$ - order of the matrix.

If the matrix is perfectly consistent then the CI will be zero as the maximum eigenvalue will be equal to the order of the matrix. In AHP, pairwise comparison matrices are not forced to be perfectly consistent; in other words, the CI value can be greater than zero. An approximate estimate for the maximum eigenvalue can be calculated by the method provided in McIntyre and Parfitt (1998). Details of this method can also be found in Salem et al. (2014).

The consistency of the judgment can be quantified by the Consistency Ratio (CR), which is calculated using Eq. (3):

$$
C R=\frac{C I}{R I} \text {. }
$$

Random Index (RI) values for various sizes of comparison matrices can be found in Saaty (1980) and Alonso, Lamata (2006). It should be emphasized that while making a large number of comparisons, minimizing a CR does not necessarily result in better judgment. Although good decisions are mostly based on consistent judgment, the opposite is not always true. Generally the permissible upper limit for CR is considered to be 0.10 (Saaty 1980). If the CR is found to be above 0.10 then the pairwise comparison values should be revised so that the $\mathrm{CR}$ value is reduced to 0.10 .

Step 6: Final Evaluation of the Alternatives for Decision-Making. The factors having an impact on the $\mathrm{ABC}$ decision-making process will have different relevancies in different projects. It is, therefore, necessary to evaluate these factors in a project specific manner to determine whether $\mathrm{ABC}$ or traditional construction is more suitable for the project. Thus, $\mathrm{ABC}$ is compared against traditional construction in a pairwise manner to understand the level of effectiveness that could be achieved for the objective(s) stated in each criterion. All the steps from step 2 to step 5 are repeated for each criterion. It should be noted that the decision maker should have sufficient expertise to make proper evaluations with respect to the factors used in the model.

In this step, a scale is prepared to evaluate the importance (or relevance) of each criterion or factor for the project under consideration A computerized version of the model is developed (using Microsoft Excel) to provide the user with a menu of options to select the level of relevance of each factor to the particular project. The number of options in this study was limited to five as suggested by FHWA officials during the survey and also as observed in some other studies such as the study conducted by Pan (2008).

The options with their corresponding values are: absolutely relevant -9 ; very relevant -5 ; relevant -1 ; less relevant $-1 / 5$; irrelevant $-1 / 9$. The reciprocal values are used when the other alternative is absolutely relevant or very relevant for the factor under consideration. In other words, absolutely relevant (relevance value of 9) and irrelevant (relevance value of 1/9), and very relevant (relevance value of 5) and less relevant (relevance value of $1 / 5$ ) options are used to indicate equal but opposite levels of relevancies for the alternatives.

The scores corresponding to the options selected by the user are used for the pairwise comparison of the alternatives ( $\mathrm{ABC}$ vs. traditional construction) for each criterion. Eigenvectors representing the relevance of the criteria to the project are then obtained. The final score for each alternative was calculated by using Eq. (4):

$$
\lambda=\sum_{i=1}^{n}\left(\left(\lambda_{F i}\right) \cdot\left(\lambda_{A i}\right)\right),
$$

where: $\lambda$ - overall score of the alternative; $i$ - index number for factors/criteria; $\lambda_{F i}$ - eigenvector (weight) obtained from pairwise comparison of factors; $\lambda_{A i}-$ eigenvector (weight) obtained from pairwise comparison of the alternative for each factor.

The alternative with the higher overall score is considered to be more suitable for the project.

\subsection{Phase 2: $A B C$ Technique and Procurement Method Selection Model}

Phase 2 of the model is commenced once the user selects $A B C$ as a viable option in Phase 1 . Through flowcharts, Phase 2 assists in selecting appropriate construction techniques and procurement methods given certain characteristics of the project.

ABC Alternatives Selection Model. This model was prepared using the information obtained from the literature and from case studies at hand. At first the ABCC are shortlisted based on the scope of the project (i.e. whether it is rehabilitation, repair, or replacement of an existing bridge or construction of a new bridge). The techniques to be used for accelerated construction depend mostly on the type of construction (i.e. whether the construction is over a body of water or wetland or whether the bridge is over a roadway with existing traffic, railroad or transit). The complete model is presented in Fig. 2.

Procurement Method and Contract Selection Model. In this flowchart model, the candidate procurement methods are DBB, CMR, CMA and DB. It has been observed in previous studies that some of the contracting provisions such as $\mathrm{A}+\mathrm{B}$ contracting, $\mathrm{I} / \mathrm{D}$, advance purchasing, lane rental, and phased construction can be used in conjunction with any procurement method or alone depending on the project requirements. 


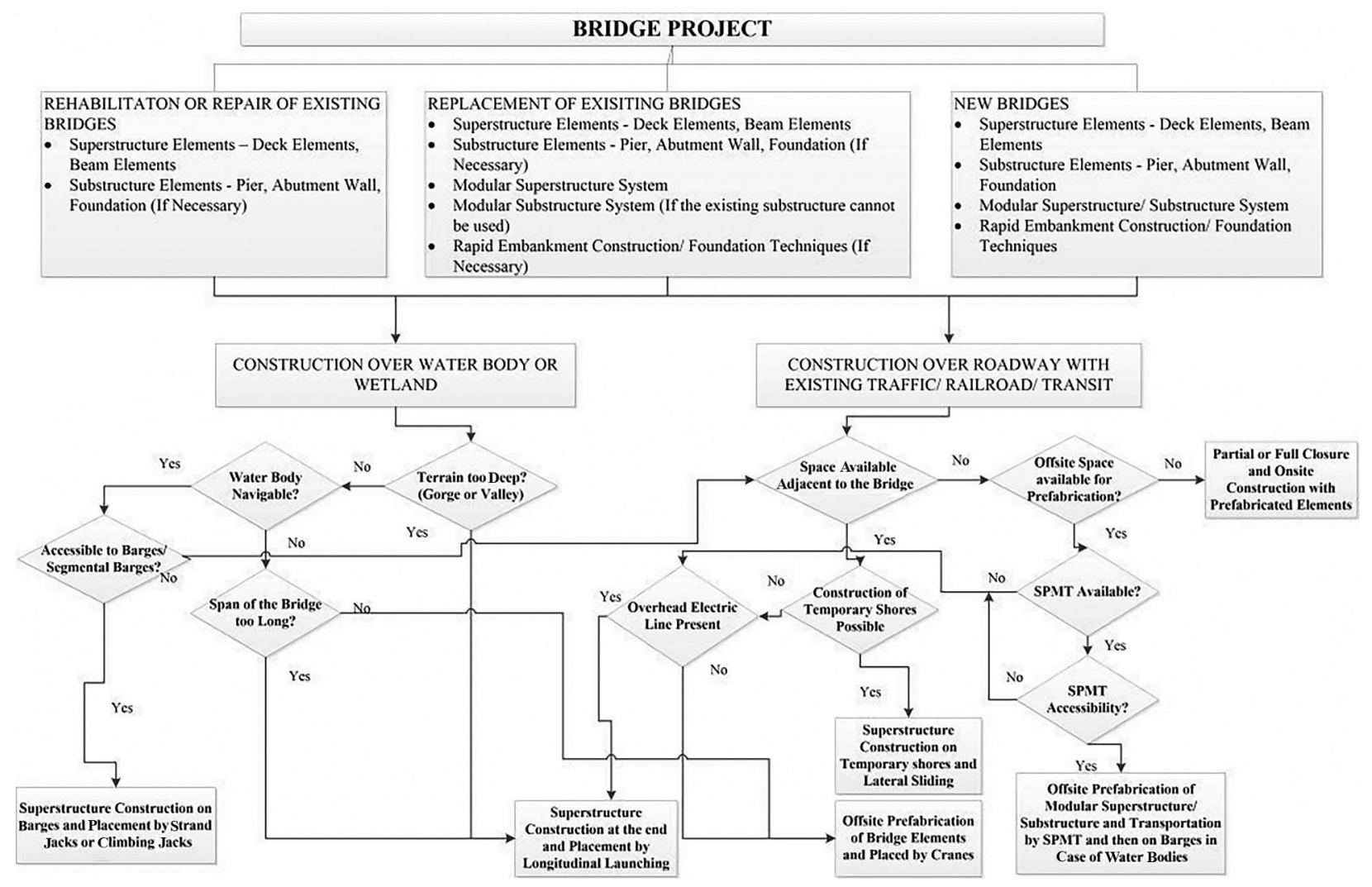

Fig. 2. ABC Alternative Selection Model

Samples of projects that involve use of $A+B$ with $I / D$, $\mathrm{DBB}$ with $\mathrm{I} / \mathrm{D}, \mathrm{DB}$ with $\mathrm{A}+\mathrm{B}$ and $\mathrm{I} / \mathrm{D}$, and negotiated lump sum emergency contract with $\mathrm{I} / \mathrm{D}$ can be found in Blanchard et al. (2009). The procurement method and contract selection model is presented in Fig. 3.

\section{Case Study}

This section presents the application of the AHP model presented in this paper to a bridge project in New York State. A brief description of how pairwise comparison matrix was formed is provided, followed by the output generated by the model. Since the flow charts developed in Phase 2 are mainly based on case studies, this part focuses solely on validation of the AHP model.

The factors most likely to have an impact on the decision-making process with regards to whether $A B C$ or traditional construction methods should be utilized in a project were identified from literature review, surveys and interviews. Nineteen factors were listed as decision criteria under the overall goal. To keep the model simple only one level of hierarchy was considered. The hierarchy created is presented in Fig. 4.

A new survey was prepared and sent to a group of NYSDOT officials, which included project managers and design engineers. The identities of the individuals were kept anonymous. The survey constituted all the factors identified in the previous step that may affect the decision-making process. Participants were asked to rate these factors on a scale of 1 to 9 , so as to reflect these factors' relevance towards selecting $\mathrm{ABC}$ over traditional construction. A total of ten responses were received. The geometric mean of the scores for each factor was calculated as suggested by Saaty (2012) and these mean values were used to indicate the weight of each factor in terms of its importance ( $W$ in Fig. 5). To populate the pairwise comparison matrix, each factor's relevance value was divided by other factors' relevance values and the outcome was recorded at the corresponding row/column intersection of the pairwise comparison matrix. For accurate results, the relative weights were kept in decimal figures rather than in rounded values. The resultant matrix is shown in Fig. 5. The letters denote the factors adjacent to them.

Eigenvectors were calculated using the average of normalized column technique. It should be noted that the procedure followed in populating the pairwise comparison matrix (i.e. calculating the ratio of relevance value of one factor to the other) resulted in a special case in terms of the calculation of factor weights. As a result of using ratios in pairwise comparisons, the resultant relative weight value for each factor coincides with the ratio of each factor's relevance value to the sum of all relevance values. If, however, the user decides to use values other than the ratio of relevance values in the pairwise comparison matrix (such as a whole number derived by rounding the ratio values), AHP procedures 


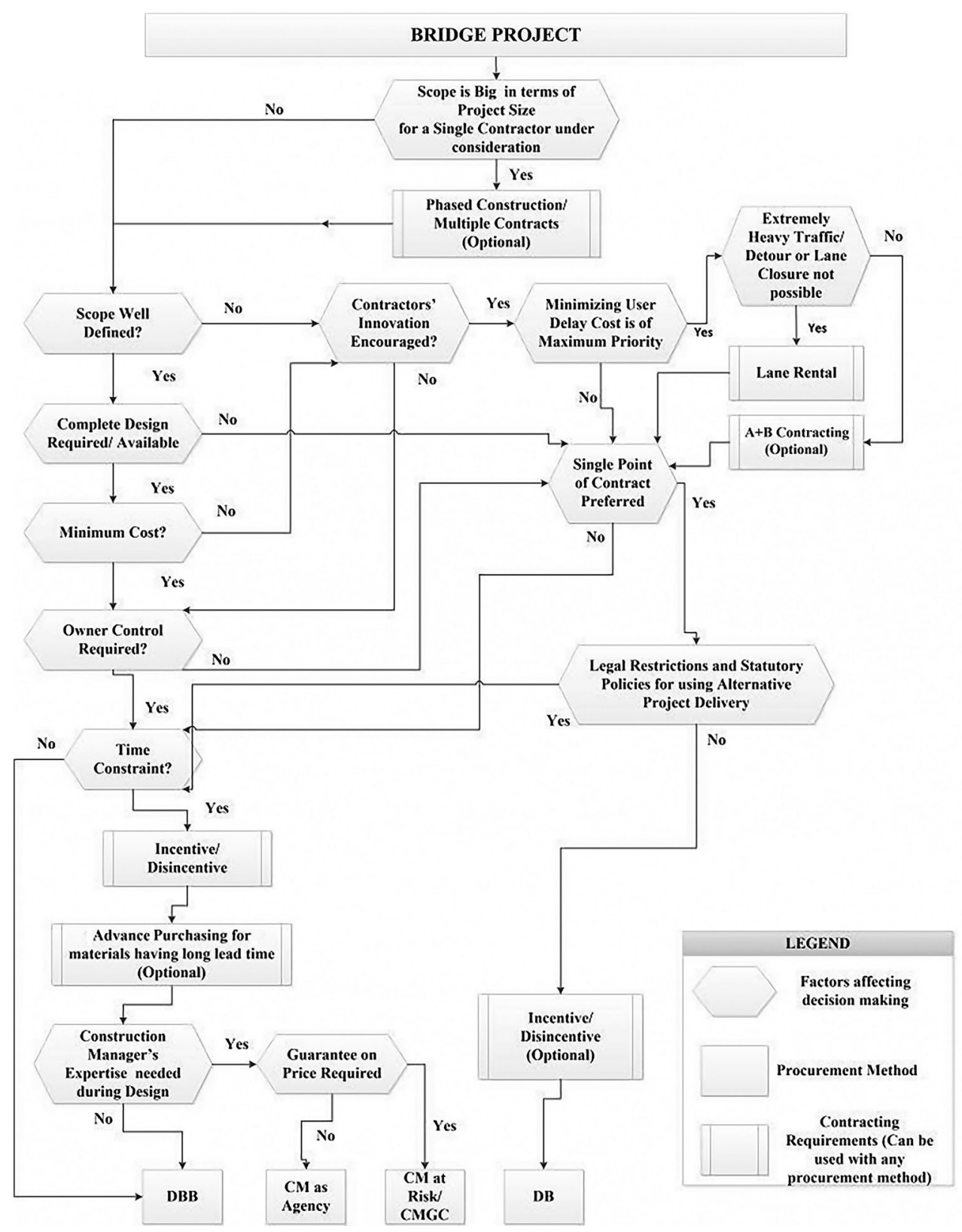

Fig. 3. Procurement method and contract selection model

should be used to calculate factor weights and to check the consistency of the pairwise comparison matrix. In the model presented, since exact ratios of the weights are used in the pairwise comparison matrix, the CI value is equal to zero.

The $\mathrm{ABC}$ vs. traditional construction decisionmaking model was utilized on the Cross Bay Boulevard viaduct project over the North Channel in Queens, NY. The bridge is approximately 2842 feet long, consists of 34 spans, and has 3 lanes. Some of the elements used for the project are cylinder piles, precast pier caps forms, prestressed I beams, diaphragm forms, partial depth precast deck panels. One of the issues faced was cracking tendency of the deck joints. The necessary information for the model was obtained from the NYSDOT official involved in the project. The model inputs and the results are presented in Tables 2 and 3 respectively. Table 2 shows the interface where the user is asked to select how relevant or important each factor was for this particular project. Depending on these inputs, points for both $\mathrm{ABC}$ and traditional construction alternatives were obtained for each factor. Points under the columns 'weighted traditional' and 'weighted ABC' represent how suitable the construction alternative (i.e. higher points represent higher suitability and vice versa) is for each factor considered in the model. The alternative with higher overall point, $\mathrm{ABC}$ in this case, is considered to be more suitable for the project. The contribution of the score obtained from each factor is provided in a graphical representation, as shown in Fig. 6. 


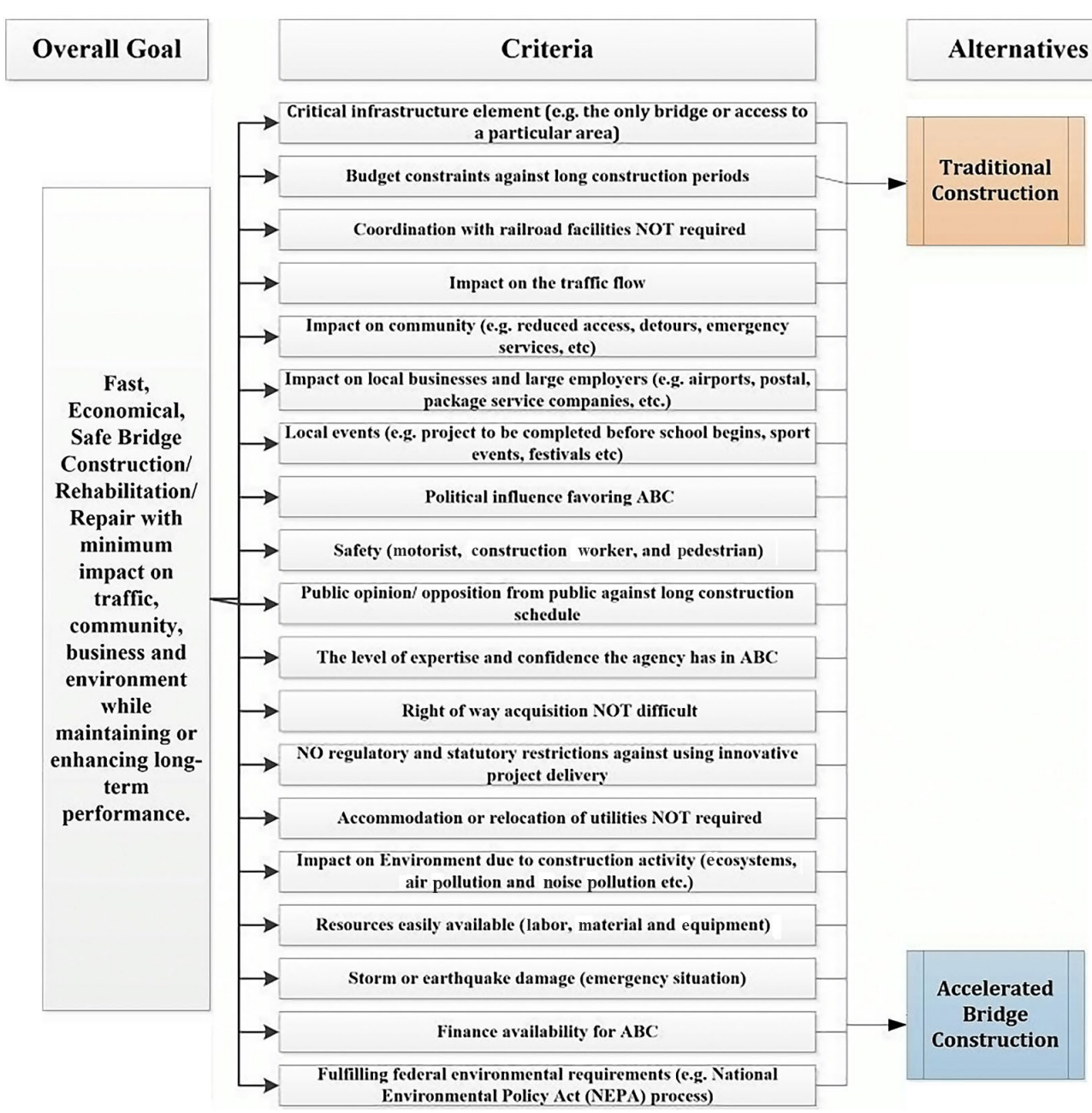

Fig. 4. Hierarchy for $\mathrm{ABC}$ vs. traditional construction decision-making framework

\begin{tabular}{|c|c|c|c|c|c|c|c|c|c|c|c|c|c|c|c|c|c|c|c|c|c|}
\hline & & & $A$ & B & C & $\mathbf{D}$ & $\mathbf{E}$ & $\mathbf{F}$ & G & $\mathbf{H}$ & I & $\mathbf{J}$ & $\mathbf{K}$ & $\mathbf{L}$ & $\mathbf{M}$ & $\mathbf{N}$ & o & $\mathbf{P}$ & Q & $\mathbf{R}$ & s \\
\hline PAIRWISE COMPARISON MATRIX & & $\mathbf{w}$ & 7.5 & 7.5 & 7.2 & 6.8 & 6.2 & 6.2 & 5.7 & 5.3 & 4.9 & 4.6 & 4.6 & 4.2 & 4.2 & 4 & 3.5 & 3.4 & 3.3 & 3 & 2.9 \\
\hline Critical infrastructure element & $A$ & 7.5 & 1.0 & 1.0 & 1.0 & 1.1 & 1.2 & 1.2 & 1.3 & 1.4 & 1.5 & 1.6 & 1.6 & 1.8 & 1.8 & 1.9 & 2.1 & 2.2 & 2.3 & 2.5 & 2.6 \\
\hline Budget Constraints against long construction periods & B & 7.5 & $1 / 1$ & 1.0 & 1.0 & 1.1 & 1.2 & 1.2 & 1.3 & 1.4 & 1.5 & 1.6 & 1.6 & 1.8 & 1.8 & 1.9 & 2.1 & 2.2 & 2.3 & 2.5 & 2.6 \\
\hline Coordination with railroad facilities NOT required & $\mathbf{C}$ & 7.2 & $1 / 1$ & $1 / 1$ & 1.0 & 1.1 & 1.2 & 1.2 & 1.3 & 1.4 & 1.5 & 1.6 & 1.6 & 1.7 & 1.7 & 1.8 & 2.1 & 2.1 & 2.2 & 2.4 & 2.5 \\
\hline Impact on the traffic flow & $\mathbf{D}$ & 6.8 & $1 / 1.1$ & $1 / 1.1$ & $1 / 1.1$ & 1.0 & 1.1 & 1.1 & 1.2 & 1.3 & 1.4 & 1.5 & 1.5 & 1.6 & 1.6 & 1.7 & 1.9 & 2.0 & 2.1 & 2.3 & 2.3 \\
\hline Impact on community & $\mathbf{E}$ & 6.2 & $1 / 1.2$ & $1 / 1.2$ & $1 / 1.2$ & $1 / 1.1$ & 1.0 & 1.0 & 1.1 & 1.2 & 1.3 & 1.3 & 1.3 & 1.5 & 1.5 & 1.6 & 1.8 & 1.8 & 1.9 & 2.1 & 2.1 \\
\hline Impact on local businesses/ large employers & $\mathbf{F}$ & 6.2 & $1 / 1.2$ & $1 / 1.2$ & $1 / 1.2$ & $1 / 1.1$ & $1 / 1$ & 1.0 & 1.1 & 1.2 & 1.3 & 1.3 & 1.3 & 1.5 & 1.5 & 1.6 & 1.8 & 1.8 & 1.9 & 2.1 & 2.1 \\
\hline Local events & G & 5.7 & $1 / 1.3$ & $1 / 1.3$ & $1 / 1.3$ & $1 / 1.2$ & $1 / 1.1$ & $1 / 1.1$ & 1.0 & 1.1 & 1.2 & 1.2 & 1.2 & 1.4 & 1.4 & 1.4 & 1.6 & 1.7 & 1.7 & 1.9 & 2.0 \\
\hline Political Influence favoring $A B C$ & $\mathbf{H}$ & 5.3 & $1 / 1.4$ & $1 / 1.4$ & $1 / 1.4$ & $1 / 1.3$ & $1 / 1.2$ & $1 / 1.2$ & $1 / 1.1$ & 1.0 & 1.1 & 1.2 & 1.2 & 1.3 & 1.3 & 1.3 & 1.5 & 1.6 & 1.6 & 1.8 & 1.8 \\
\hline Safety of commuters and workers & I & 4.9 & $1 / 1.5$ & $1 / 1.5$ & $1 / 1.5$ & $1 / 1.4$ & $1 / 1.3$ & $1 / 1.3$ & $1 / 1.2$ & $1 / 1.1$ & 1.0 & 1.1 & 1.1 & 1.2 & 1.2 & 1.2 & 1.4 & 1.4 & 1.5 & 1.6 & 1.7 \\
\hline $\begin{array}{l}\text { Public opinion/opposition from public against long } \\
\text { construction schedule }\end{array}$ & $\mathbf{J}$ & 4.6 & $1 / 1.6$ & $1 / 1.6$ & $1 / 1.6$ & $1 / 1.5$ & $1 / 1.3$ & $1 / 1.3$ & $1 / 1.2$ & $1 / 1.2$ & $1 / 1.1$ & 1.0 & 1.0 & 1.1 & 1.1 & 1.2 & 1.3 & 1.4 & 1.4 & 1.5 & 1.6 \\
\hline Expertise/ confidence in ABC & $\mathbf{K}$ & 4.6 & $1 / 1.6$ & $1 / 1.6$ & $1 / 1.6$ & $1 / 1.5$ & $1 / 1.3$ & $1 / 1.3$ & $1 / 1.2$ & $1 / 1.2$ & $1 / 1.1$ & $1 / 1$ & 1.0 & 1.1 & 1.1 & 1.2 & 1.3 & 1.4 & 1.4 & 1.5 & 1.6 \\
\hline Right of way acquisition NOT difficult & $\mathbf{L}$ & 4.2 & $1 / 1.8$ & $1 / 1.8$ & $1 / 1.7$ & $1 / 1.6$ & $1 / 1.5$ & $1 / 1.5$ & $1 / 1.4$ & $1 / 1.3$ & $1 / 1.2$ & $1 / 1.1$ & $1 / 1.1$ & 1.0 & 1.0 & 1.1 & 1.2 & 1.2 & 1.3 & 1.4 & 1.4 \\
\hline $\begin{array}{l}\text { NO regulatory and statutory restrictions against using } \\
\text { Innovative Project Delivery }\end{array}$ & $\mathbf{M}$ & 4.2 & $1 / 1.8$ & $1 / 1.8$ & $1 / 1.7$ & $1 / 1.6$ & $1 / 1.5$ & $1 / 1.5$ & $1 / 1.4$ & $1 / 1.3$ & $1 / 1.2$ & $1 / 1.1$ & $1 / 1.1$ & $1 / 1$ & 1.0 & 1.1 & 1.2 & 1.2 & 1.3 & 1.4 & 1.4 \\
\hline Accommodation/relocation of utilities NOT required & $\mathbf{N}$ & 4 & $1 / 1.9$ & $1 / 1.9$ & $1 / 1.8$ & $1 / 1.7$ & $1 / 1.6$ & $1 / 1.6$ & $1 / 1.4$ & $1 / 1.3$ & $1 / 1.2$ & $1 / 1.2$ & $1 / 1.2$ & $1 / 1.1$ & $1 / 1.1$ & 1.0 & 1.1 & 1.2 & 1.2 & 1.3 & 1.4 \\
\hline Impact on environment due to construction acvitity & $\mathbf{o}$ & 3.5 & $1 / 21$ & $1 / 2.1$ & $1 / 2.1$ & $1 / 1.9$ & $1 / 1.8$ & $1 / 1.8$ & $1 / 1.6$ & $1 / 1.5$ & $1 / 1.4$ & $1 / 1.3$ & $1 / 1.3$ & $1 / 1.2$ & $1 / 1.2$ & $1 / 1.1$ & 1.0 & 1.0 & 1.1 & 1.2 & 1.2 \\
\hline Rescurces easily Available & $\mathbf{P}$ & 3.4 & $1 / 22$ & $1 / 2.2$ & $1 / 2.1$ & $1 / 2$ & $1 / 1.8$ & $1 / 1.8$ & $1 / 1.7$ & $1 / 1.6$ & $1 / 1.4$ & $1 / 1.4$ & $1 / 1.4$ & $1 / 1.2$ & $1 / 1.2$ & $1 / 1.2$ & $1 / 1$ & 1.0 & 1.0 & 1.1 & 1.2 \\
\hline Storm or earthquake damage (emergency situation) & Q & 3.3 & $1 / 23$ & $1 / 2.3$ & $1 / 2.2$ & $1 / 2.1$ & $1 / 1.9$ & $1 / 1.9$ & $1 / 1.7$ & $1 / 1.6$ & $1 / 1.5$ & $1 / 1.4$ & $1 / 1.4$ & $1 / 1.3$ & $1 / 1.3$ & $1 / 1.2$ & $1 / 1.1$ & $1 / 1$ & 1.0 & 1.1 & 1.1 \\
\hline Finance availability for $\mathrm{ABC}$ & $\mathbf{R}$ & 3 & $1 / 25$ & $1 / 2.5$ & $1 / 2.4$ & $1 / 2.3$ & $1 / 2.1$ & $1 / 2.1$ & $1 / 1.9$ & $1 / 1.8$ & $1 / 1.6$ & $1 / 1.5$ & $1 / 1.5$ & $1 / 1.4$ & $1 / 1.4$ & $1 / 1.3$ & $1 / 1.2$ & $1 / 1.1$ & $1 / 1.1$ & 1.0 & 1.0 \\
\hline Fulfilling federal environmental requirements & $\mathbf{s}$ & 29 & $1 / 26$ & $1 / 2.6$ & $1 / 2.5$ & $1 / 2.3$ & $1 / 2.1$ & $1 / 2.1$ & $1 / 2$ & $1 / 1.8$ & $1 / 1.7$ & $1 / 1.6$ & $1 / 1.6$ & $1 / 1.4$ & $1 / 1.4$ & $1 / 1.4$ & $1 / 1.2$ & $1 / 1.2$ & $1 / 1.1$ & $1 / 1$ & 1.0 \\
\hline
\end{tabular}

Fig. 5. Pairwise comparison of factors with scores 


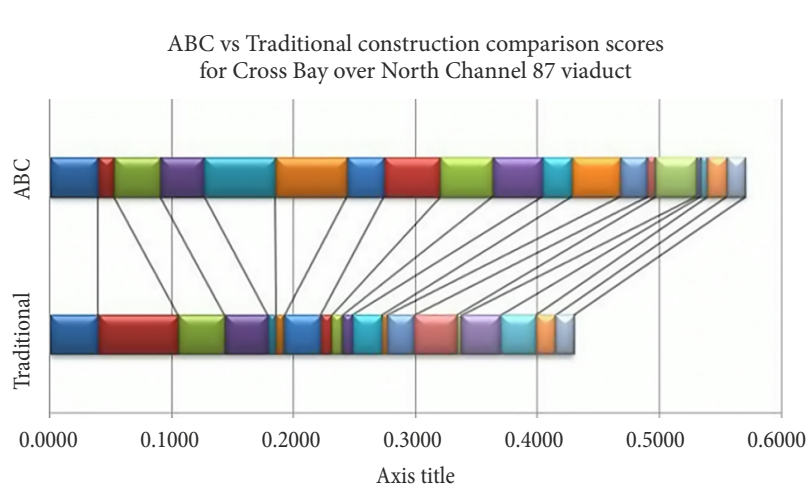

Critical infrastructure element

Budget constraints against long construction periods

Coordination with railroad facilities NOT required

Impact on the traffic flow

Impact on community

Impact on local businesses/ large employers

Local events

Political influence Favoring ABC

Safety of commuters and workers

Public opinion/opposition from public against long construction schedule

Expertise/confidence in $\mathrm{ABC}$

Right of way acquisition NOT difficult

NO regulatory and statutory restrictions against using innovative project delivery

Accommodation/relocation of utilities NOT required

Impact on environment due to construction acvitity

Resources easily available

Storm or earthquake damage (emergency situation)

Finance availability for ABC

Fulfilling Federal environmental requirements

Fig. 6. Graphical representation of the relative importance of $\mathrm{ABC}$ decision-making factors

Table 2. ABC vs. traditional decision-making model inputs for Cross Bay over North Channel 87 viaduct, NY

\begin{tabular}{|l|l|}
\hline \multicolumn{1}{|c|}{ Factors favoring ABC } & \multicolumn{1}{l|}{ Relevance level } \\
\hline Critical infrastructure element & relevant \\
\hline Budget constraints against long construction periods & less relevant \\
\hline Coordination with railroad facilities NOT required & relevant \\
\hline Impact on the traffic flow & relevant \\
\hline Impact on community & absolutely relevant \\
\hline Impact on local businesses/large employers & absolutely relevant \\
\hline Local events & relevant \\
\hline Political influence favoring ABC & very relevant \\
\hline Safety of commuters and workers & very relevant \\
\hline Public opinion/opposition against long construction schedule & very relevant \\
\hline Expertise/confidence in ABC & relevant \\
\hline Right of way acquisition NOT difficult & absolutely relevant \\
\hline NO regulatory and statutory restrictions against using innovative contracting methods & relevant \\
\hline Accommodation/relocation of utilities NOT required & less relevant \\
\hline Impact on environment due to construction activity & absolutely relevant \\
\hline Resources easily available & irrelevant \\
\hline Storm or earthquake damage (emergency situation) & less relevant \\
\hline Finance availability for ABC & relevant \\
\hline Fulfilling federal environmental requirements & relevant \\
\hline
\end{tabular}

Table 3. ABC vs. traditional decision-making model results for Cross Bay Boulevard viaduct over North Channel, NY

\begin{tabular}{|l|c|c|c|c|c|}
\hline \multicolumn{1}{|c|}{ Factors favoring ABC } & Weights & Traditional & ABC & Weighted traditional & Weighted ABC \\
\hline Critical infrastructure element & 0.079 & 0.500 & 0.500 & 0.040 & 0.040 \\
\hline Budget constraints against long construction periods & 0.079 & 0.833 & 0.167 & 0.066 & 0.013 \\
\hline Coordination with railroad facilities NOT required & 0.076 & 0.500 & 0.500 & 0.038 & 0.038 \\
\hline Impact on the traffic flow & 0.072 & 0.500 & 0.500 & 0.036 & 0.036 \\
\hline Impact on community & 0.065 & 0.100 & 0.900 & 0.007 & 0.059 \\
\hline Impact on local businesses/large employers & 0.065 & 0.100 & 0.900 & 0.007 & 0.059 \\
\hline Local events & 0.060 & 0.500 & 0.500 & 0.030 & 0.030 \\
\hline Political influence favoring ABC & 0.056 & 0.167 & 0.833 & 0.009 & 0.047 \\
\hline Safety of commuters and workers & 0.052 & 0.167 & 0.833 & 0.009 & 0.043 \\
\hline $\begin{array}{l}\text { Public opinion/opposition from public against long } \\
\text { construction schedule }\end{array}$ & 0.048 & 0.167 & 0.833 & 0.008 & 0.040 \\
\hline Expertise/confidence in ABC & 0.048 & 0.500 & 0.500 & 0.024 & 0.024 \\
\hline
\end{tabular}


End of Table 3

\begin{tabular}{|l|c|c|c|c|c|}
\hline \multicolumn{1}{|c|}{ Factors favoring ABC } & Weights & Traditional & ABC & Weighted traditional & Weighted ABC \\
\hline Right of way acquisition NOT difficult & 0.044 & 0.100 & 0.900 & 0.004 & 0.040 \\
\hline $\begin{array}{l}\text { NO regulatory and statutory restrictions against } \\
\text { using innovative project delivery }\end{array}$ & 0.044 & 0.500 & 0.500 & 0.022 & 0.022 \\
\hline Accommodation/relocation of utilities NOT required & 0.042 & 0.833 & 0.167 & 0.035 & 0.007 \\
\hline Impact on environment due to construction activity & 0.037 & 0.100 & 0.900 & 0.004 & 0.033 \\
\hline Resources easily available & 0.036 & 0.900 & 0.100 & 0.032 & 0.004 \\
\hline Storm or earthquake damage (emergency situation) & 0.035 & 0.833 & 0.167 & 0.029 & 0.006 \\
\hline Finance availability for ABC & 0.032 & 0.500 & 0.500 & 0.016 & 0.016 \\
\hline Fulfilling federal environmental requirements & 0.031 & 0.500 & 0.500 & 0.015 & 0.015 \\
\hline & & & & 0.430 & 0.570 \\
\hline
\end{tabular}

Notes: $\mathrm{ABC}$ score $=0.570$; traditional construction score $=0.430$; construction type recommended: ABC.

\section{Conclusions}

This paper presents a two phased decision-making framework for accelerating bridge construction based on a thorough review of existing literature, practices employed by state DOTs, and the experiences of NYSDOT bridge professionals. The AHP based $\mathrm{ABC}$ vs. traditional construction decision-making model (Phase 1) can assist users in higher level decision-making. The model included qualitative factors such as the importance of infrastructure to the surrounding community in terms of providing access routes to emergency services, schools and businesses. It also included factors that relate to the negotiation and coordination of challenges between various sectors of transportation such as railroads and waterways, mostly when utilities are involved. The effects of such factors are difficult to quantify. AHP is deemed to be a suitable method to develop a decision support tool as the available information could be used to generate a representation of experts' opinion based on the relative importance of one factor over another and the relative relevancy of these factors for a given project.

Phase 2 is comprised of two flowcharts that assist in selecting appropriate construction techniques and proper contracting alternatives, respectively. These flowcharts provide a strategic framework to the DOT officials to shortlist the suitable and feasible alternatives.

The models are expected to make the decision process in bridge construction projects more objective and justifiable. This study is anticipated to assist in the development of more efficient management strategies for highway bridges by reducing the negative impacts associated with bridge repair and rehabilitation projects.

\section{Recommendations}

The scope of this study mainly focused on providing higher-level decision-making procedures considering generalized factors with regards to economic and social aspects of accelerated construction. One of the potential areas of future research would be to conduct detailed benefit/cost analysis in certain conditions to precisely determine the technical and economic feasibility of each
$A B C$ alternative under different scenarios. Such studies would create possibilities for development of more accurate decision-making tools that feature quantitative evaluations at higher levels of detail. Research focusing on the environmental impacts of various bridge construction methods and whether/how accelerated construction techniques can be used to minimize those impacts could broaden the factors and alternatives considered in the $\mathrm{ABC}$ decision-making procedures. In addition, the flowcharts in Phase 2 were mainly developed based on the available information obtained from case studies at hand. These flowcharts can be further improved based on the results of case studies to be undertaken in the future.

\section{Acknowledgements}

This study was supported by the University Transportation Research Center, Region 2 and the University Transportation Center: Transportation for Livability by Integrating Vehicles and the Environment (TranLIVE).

The authors would also like to thank NYSDOT officials Wahid Albert, Mathew Royce, Richard Marchione and FHWA official Timothy Cupples for their valuable input and suggestions.

\section{References}

AASHTO. 2007. Accelerating Project Delivery. Publication TIF7-1. American Association of State Highway and Transportation Officials (AASHTO), US. 56 p. Available from Internet: http://downloads.transportation.org/TIF7-1.pdf

Alonso, J. A.; Lamata, M. T. 2006. Consistency in the analytic hierarchy process: a new approach, International Journal of Uncertainty, Fuzziness and Knowledge-Based Systems 14(4): 445-459. https://doi.org/10.1142/S0218488506004114

ASCE. 2013. Bridges, in 2013 Report Card for America's Infrastructure. American Society of Civil Engineers (ASCE). Available from Internet: http://www.infrastructurereportcard.org/a/\#p/bridges/overview

Blanchard, B. A.; Bohuslav, T. R.; Schneider, C.; Anderson, S.; Schexnayder, C. J.; DeWitt, S. D.; Raymond, G.; Sheffield, R. 2009. Best Practices in Accelerated Construction Techniques. NCHRP Project 20-68A, Scan 07-02. National Cooperative 
Highway Research Program (NCHRP), US. 192 p. Available from Internet: http://onlinepubs.trb.org/onlinepubs/ nchrp/docs/NCHRP20-68A_07-02.pdf

Carpenter, B.; Fekpe, E.; Gopalakrishna, D. 2003. PerformanceBased Contracting for the Highway Construction Industry: an Evaluation of the Use of Innovative Contracting and Performance Specification in Highway Construction. Battelle Memorial Institute, US. 49 p.

Culmo, M. P. 2011. Accelerated Bridge Construction: Experience in Design, Fabrication and Erection of Prefabricated Bridge Elements and Systems. Final Manual. Publication No HIF12-013. Federal Highway Administration (FHWA), US Department of Transportation. 347 p. Available from Internet: https://www.fhwa.dot.gov/bridge/abc/docs/abcmanual.pdf

Culmo, M. P. 2009. Connection Details for Prefabricated Bridge Elements and Systems. Publication No FHWA-IF-09-010. Federal Highway Administration (FHWA), US Department of Transportation. 568 p. Available from Internet: https:// www.fhwa.dot.gov/bridge/prefab/if09010/report.pdf

Doolen, T.; Saeedi, A.; Emami, S. 2011. Accelerated Bridge Construction $(A B C)$ Decision Making and Economic Modeling Tool. Final Report. Project TPF-5(221). Oregon Department of Transportation, US. $201 \mathrm{p}$.

FHWA. 2012. Prefabricated Bridge Elements and Systems (PBES) Definitions. Federal Highway Administration (FHWA), US Department of Transportation. Available from Internet: http://www.fhwa.dot.gov/bridge/abc/prefab_def.cfm

FHWA. 2007. Manual on Use of Self-Propelled Modular Transporters to Remove and Replace Bridges. Publication No FHWA-HIF-07-022. Federal Highway Administration (FHWA), US Department of Transportation. $118 \mathrm{p}$. Available from Internet: https://www.fhwa.dot.gov/bridge/ pubs/07022/hif07022.pdf

Fishman, E.; Kirkpatrick, E.; Ellis, L. P. G. 2009. Legal Research Digest 51: Major Legal Issues for Highway Public-Private Partnerships. National Cooperative Highway Research Program (NCHRP). 39 p. https://doi.org/10.17226/23324

Hall, J.; Migliaccio, G.; Tarefder, R.; Ghorai, S. 2010. Road Lifecycle Innovative Financing (Road LIFE) 2010. Report No NM08ADM-01. Research Bureau, NM Department of Transportation, US. 107 p. Available from Internet: http://dot.state.nm.us/content/dam/nmdot/Research/ NM08ADM-01\%20Road\%20LIFE\%20Innovative\%20Financing\%202010.pdf

Hancher, D. E. 1999. Contracting Methods for Highway Construction. Committee on Construction Management, Transportation Research Board, US. 7 p.

Lee, E.-B.; Thomas, D. K. 2007. State-of-practice technologies on accelerated urban highway rehabilitation: I-15 California experience, Journal of Construction Engineering and Management 133(2): 105-113.

https://doi.org/10.1061/(ASCE)0733-9364(2007)133:2(105)

Mahdi, I. M.; Alreshaid, K. 2005. Decision support system for selecting the proper project delivery method using analytical hierarchy process (AHP), International Journal of Project Management 23(7): 564-572.

https://doi.org/10.1016/j.ijproman.2005.05.007

McIntyre, C.; Parfitt, M. K. 1998. Decision support system for residential land development site selection process, Journal of Architectural Engineering 4(4): 125-131. https://doi.org/10.1061/(ASCE)1076-0431(1998)4:4(125)

Pan, N.-F. 2008. Fuzzy AHP approach for selecting the suitable bridge construction method, Automation in Construction 17(8): 958-965.

https://doi.org/10.1016/j.autcon.2008.03.005
Ralls, M. L.; Tang, B.; Bhidé, S.; Brecto, B.; Calvert, E.; Capers, H.; Dorgan, D.; Matsumoto, E.; Napier, C.; Nickas, W.; Russell, H. 2005. Prefabricated Bridge Elements and Systems in Japan and Europe. Publication No FHWA-PL-05-003. Federal Highway Administration (FHWA), US Department of Transportation. 65 p. Available from Internet: https:// international.fhwa.dot.gov/prefab_bridges/pl05003.pdf

Reichman, S. 1976. Conceptual problems in evaluation of travel time, Transportation Research Record 587: 24-29.

Saaty, T. L. 2012. Decision Making for Leaders: the Analytic Hierarchy Process for Decisions in a Complex World. 3rd revised edition. RWS Publications. 323 p.

Saaty, T. L. 1980. The Analytic Hierarchy Process: Planning, Priority Setting, Resource Allocation. Mcgraw-Hill. 287 p.

Salem, O. 2013. Accelerating the Construction Process of Highway Bridges. Final Report. UTRC-RF Project No 49111-2921. Syracuse University, US. 141 p. Available from Internet: http://www.utrc2.org/sites/default/files/pubs/AcceleratingConstruction-Process.pdf

Salem, O.; Ghorai, S.; Salman, B.; Aboutaha, R. 2014. A decision support framework for accelerated bridge construction, in TRB 93rd Annual Meeting Compendium of Papers, 12-16 January 2014, Washington, DC, US, 1-21.

Salem, O.; Salman, B.; Aboutaha, R. 2013. Accelerating the Construction Process of Highway Bridges. Final Report. UTRCRF Project No. 49111-29-21. University Transportation Research Center - Region 2, US. 141 p. Available from Internet: http://www.utrc2.org/sites/default/files/pubs/ Accelerating-Construction-Process.pdf

Tang, B. 2006. Framework for prefabricated bridge elements and systems (PBES) decision-making, in Proceedings of the Second US-Taiwan Bridge Engineering Workshop, 21-22 September 2006, San Francisco, California, US. 21 p.

UDOT. 2010. Accelerated Bridge Construction Decision Making Process 2010. Utah Department of Transportation (UDOT), US. 7 p. Available from Internet: https://www.udot.utah. gov/public/ucon/uconowner.gf?n=13955921501274833

Youssef, M. A.; Anumba, C. J.; Thorpe, T. 2005. Intelligent selection of concrete bridge construction methods in Egypt, in Proceedings of the 2005 ASCE International Conference on Computing in Civil Engineering, 12-15 July 2005, Cancun, Mexico, 1-14. https://doi.org/10.1061/40794(179)164 